\title{
Erratum to: Duplex Doppler Ultrasound Examination of the Portal Venous System: An Emerging Novel Technique for the Estimation of Portal Vein Pressure
}

\author{
Ashwani K. Singal · Masood Ahmad •
}

Roger D. Soloway

Published online: 20 April 2010

(C) Springer Science+Business Media, LLC 2010

\section{Erratum to: Dig Dis Sci}

DOI 10.1007/s10620-009-0887-0

The article was published with the following errors:

1. Second line of Table 3 should read " $\pi \times$ portal vein radius $^{2}$,

2. Section entitled Pitfalls in the Present Technique of DDUS and Future Prospects, first paragraph, "(Table 3)" should be "(Table 1)"

3. Reference 36 should read "Iwao T, Oho K, Sakai T, Sato M, Yamayaki M, Toyonnaga A, et al. Non- invasive hemodynamic measurements of superior mesenteric artery in the prediction of portal pressure response to propranolol. J Hepatol. 1998;28:847-855."

4. Reference 41 should read "Thalheimer V, Leandro G, Samonakis DN, Triantos CK, Hatch D, Borroughs AK. Assessment of the agreement between wedge hepatic vein pressure and portal vein pressure in cirrhotic patients. Dig Liv Dis. 2005;37:601-608."

The online version of the original article can be found under doi: 10.1007/s10620-009-0887-0.

\footnotetext{
A. K. Singal $(\varangle) \cdot$ R. D. Soloway

Division of Gastroenterology, Department of Internal Medicine,

University of Texas Medical Branch, 301 Univ Blvd, Galveston,

TX 77555-0764, USA

e-mail: aksingal@utmb.edu

R. D. Soloway

e-mail: rsoloway@utmb.edu
}

\section{Ahmad}

Division of Cardiology, Department of Internal Medicine, University of Texas Medical Branch, Galveston, TX, USA

e-mail: mahmad@utmb.edu 